\title{
GENERALIZAÇÃO DA FORMA EMPRESA EXPRESSA NA POLÍTICA FEDERAL DE CULTURA - UM EXPERIMENTO DA RENOVAÇÃO DO NEOLIBERALISMO
}

\author{
Generalization of the Company Form Revealed in the Federal Culture Policy - \\ na experimente in the neoliberalismo
}

\author{
Patricia Tometich' \\ Rosimeri Carvalho \\ Rodrigo Gameiro Guimarães ${ }^{3}$
}

\begin{abstract}
Resumo
Elaboramos uma análise das inter-relações entre os discursos das políticas federais de cultura no Brasil com a renovação do neoliberalismo e com a teoria econômica das organizações. Construímos um levantamento histórico das recentes políticas públicas federais de cultura e identificamos três momentos: (1) a década de 1990 marcada pelo discurso do estado mínimo, relacionado às políticas de cultura direcionadas pelas leis de incentivo fiscal; (2) nos anos 2000, com políticas voltadas à diversidade e foco nas manifestações populares; e (3) a partir de 2010, percebemos políticas que reconfiguram o foco econômico da década de 1990, com as teorias do empreendedorismo e da regulação e o novo neoliberalismo, produzindo significados e significantes, como Indústria e Economia Criativa. Observamos que a Política Federal de Economia Criativa dissemina a generalização da forma empresa e, em consequência, do empreendedorismo, como solução para problemas sociais como geração de trabalho e renda, o que reconhecemos como um experimento inserido na renovação do neoliberalismo.
\end{abstract}

Palavras-chave: economia criativa; política cultural; neoliberalismo; teorias econômicas.

\begin{abstract}
We elaborate an analysis of the interrelations between the discourses of the federal politics of culture in Brazil with the renewal of neoliberalism and with the economic theory of the organizations. We built a historical survey of the recent federal culture public policies and identified three moments: (1) the 1990s marked by the minimal state discourse, related to culture policies directed by fiscal incentive law; (2) in the 2000s, with policies centered on diversity and focus on popular manifestation; and (3) from 2010 onwards, we noticed policies that reconfigure the economic focus of the 1990s, with the theories of entrepreneurship and regulation and the new neoliberalism, producing meanings and significant, such as Creative Industry and Creative Economy. We observe that the Federal Policy of Creative Economy disseminates the generalization of the company form and, consequently, of entrepreneurship, as a

\footnotetext{
1 Universidade Federal do Rio Grande (FURG), Laboratório Interdisciplinar Marées -FURG Campus São Lourenço do Sul. E-mail: ptometich@gmail.com

2 Professora Convidada PPGA/UFRGS. E-mail: rosicarvalho88@gmail.com

3 Vinculado à FEAC/UFAL - Maceió. E-mail: rgameiro@gmail.com
} 
Generalização da forma empresa expressa na política federal de cultura- um experimento da renovação do neoliberalismo| Patricia Tometich - Rosimeri Carvalho - Rodrigo Gameiro Guimarães

solution to social problems such as job creation and income generation, which we recognize as an experiment inserted in the renewal of neoliberalism.

Keywords: creative economy; cultural policy; neoliberalism; economic theories.

\section{Introdução}

Esta análise foi construída a partir da observação das inflexões ocorridas no âmbito das políticas federais de cultura (PFC). As Ações do Ministério da Cultura desde o primeiro governo Lula, e da gestão de Gilberto Gil, como Ministro renovaram as políticas de cultura no Brasil, dirigindo-se a grupos e manifestações culturais periféricos e marginais, mas também, atuando na estruturação de um sistema nacional da cultura a fim de melhor coordenar as ações da administração pública e integrar nestas a participação popular. Tais politicas se constituíram a partir das noções de diversidade cultural, democratização, participação e pluralidade, bem como valorização das manifestações culturais locais. Ainda assim o montante dirigido a essas ações era menor do que os recursos investidos através de lei de incentivo fiscal e foram apequenados frente a outras prioridades do Ministério da Cultura, entre elas o foco nas ações relacionadas à Economia Criativa (EC).

Desta observação decorre nosso questionamento sobre a relação dessas mudanças com o contexto nacional, e com o debate internacional e os documentos produzidos pelas agências multilaterais sobre a cultura. Tentamos localizar o contexto politico-ideológico dessas transformações como uma forma de compreender as politicas públicas de cultura para além de uma criação de um determinado governo. Buscamos compreender a relação disso com bases teóricas da economia das organizações, que parecem fundamentar as politicas de cultura, bem como os programas político-ideológicos. A partir dessa matriz de reflexão, formulamos o questionamento norteador do trabalho: Quais as convergências entre as 
Generalização da forma empresa expressa na política federal de cultura- um experimento da renovação do neoliberalismo| Patricia Tometich - Rosimeri Carvalho - Rodrigo Gameiro Guimarães

transformações das politicas federais de cultura com a renovação do quadro ideológico neoliberal que prescreve a generalização da forma empresa na solução de questões sociais?

A disseminação da forma empresa tem sido destacada no Brasil em estudos sobre o processo de empresarização abordado por Rodrigues e Silva (2006; 2019a; 2019b). Nossa análise, no entanto, não aprofunda os traços característicos da empresa, conforme destacados por estes autores. Seguimos, antes, Puello-Socarrás (2008) que enfatiza a disseminação da forma empresa conforme o entendimento de Foucault (2008). Nosso acento é, no entanto, na relação entre a renovação do quadro ideológico neoliberal que contextualiza esta generalização e o discurso científico das teorias econômicas.

Ainda que nossa proposta seja explicar um acontecimento recente, entendemos que ele é um processo histórico-discursivo. Com essa noção, procuramos recuperar o processo de construção textual e discursivo das políticas federais de cultura no Brasil, sobretudo para entender as mudanças nos objetos e principais enunciados. Em termos de construção metodológica, este texto constitui-se num ensaio teórico-empírico, pois parte de um questionamento e busca respaldo na teoria, mas faz incursões em informações documentais, para aprofundar a discussão e reflexão do conceito posto em discussão.

Pretendemos ilustrar de que forma os enunciados das politicas federais de cultura no Brasil são gestados na formação discursiva do neoliberalismo, alimentados pelo discurso científico das teorias econômicas. Para isso, percorreremos o contexto histórico, em três momentos: (1) na década de 1990 em que o discurso neoliberal do Estado Mínimo, sobretudo na área social, relaciona-se com politicas de cultura direcionadas pelas leis de incentivo fiscal; não há redução na destinação de recursos públicos, mas na intervenção do Estado na governança; (2) nos anos 2000, em que acontece a implementação de políticas voltadas à diversidade, ao fortalecimento identitário e com foco nas manifestações populares, 
Generalização da forma empresa expressa na política federal de cultura- um experimento da renovação do neoliberalismo| Patricia Tometich - Rosimeri Carvalho - Rodrigo Gameiro Guimarães

aparentando uma mudança de foco da política, mas mantendo as políticas de incentivo fiscal que beneficiam grandes eventos e empresas; e (3) a partir de 2010, percebemos reorientação dessas políticas culturais que reconfigura o foco econômico da década de 1990 com a roupagem teórica das teorias econômicas do empreendedorismo e da regulação, ajustada ao discurso do novo neoliberalismo, criando novos significados para termos como indústria cultural, e novos significantes no enunciado dessas políticas, como Indústria e Economia Criativa.

\section{Neoliberalismo, sua renovação e relação com as teorias econômicas das organizações}

Desde a década de 1970 o neoliberalismo vem sendo a resposta, reação ou saída para a crise estrutural e global do capitalismo. A proposta é manter um Estado forte para romper com sindicatos e ter controle do dinheiro, mas enfraquecido em termos de gastos sociais e intervenções econômicas. Para isso, seria necessário um ajuste fiscal com reformas para incentivar agentes econômicos, reduzindo impostos sobre rendimentos mais altos e sobre rendas (ANDERSON, 1995). O Neoliberalismo como nova ortodoxia econômica de regulação pública se deu com a implementação de políticas com essa orientação pelos EUA e Reino Unido/Grã-Bretanha em 1979 (HARVEY, 2013).

Há diferenças indiscutiveis na forma como o neoliberalismo foi instalado nos diferentes contextos, as quais não vamos tratar aqui, mas é importante lembrar que os princípios gerais são mantidos e convergem ideologicamente, constituindo um guia de práticas fundamentais (PUELLOSOCARRÁS, 2013). O bem-estar humano, na perspectiva do neoliberalismo, será alcançado quando as liberdades e capacidades empreendedoras individuais contarem com uma estrutura institucional que garanta os direitos à propriedade privada, aos livres mercados e ao livre comércio. $\mathrm{O}$ "papel do Estado é criar e preservar uma estrutura institucional apropriada a essas práticas" (HARVEY 2013, p. 13).

As crises inerentes ao capitalismo geram descrença no ideário neoliberal, e o neoliberalismo se renova, sem eliminar sua identidade 
Generalização da forma empresa expressa na política federal de cultura- um experimento da renovação do neoliberalismol Patricia Tometich - Rosimeri Carvalho - Rodrigo Gameiro Guimarães

ideológica fundamental. Tal renovação é ilustrada no quadro abaixo por quatro características centrais: presença estatal; desempenho dos mercados; (des)equilibrios da sociedade; raízes ideológicas. A essas acrescentamos a vinculação com as teorias econômicas das organizações.

\section{Quadro I - Velho e Novo Neoliberalismo}

\begin{tabular}{|c|c|c|}
\hline & "Velho" neoliberalismo & “Novo" Neoliberalismo \\
\hline Estado & Desregulamentação & Regulação. A intervenção \\
\hline $\begin{array}{l}\text { (presença enquanto } \\
\text { apparatus) }\end{array}$ & 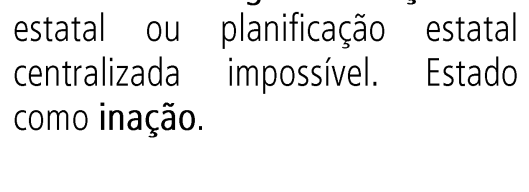 & $\begin{array}{l}\text { estatal não está permitida exceto como } \\
\text { regulação ["ação oportunista" ou } \\
\text { momentânea]. Planificação centralizada } \\
\text { impossível. O Estado de Re-ação }\end{array}$ \\
\hline $\begin{array}{l}\text { Mercado } \\
\text { (desempenhos) }\end{array}$ & \begin{tabular}{l}
\multicolumn{3}{c}{ Liberalização } & com \\
extrema liberdade [libertinagem] \\
dos mercados. Mercado como \\
produtos das "falhas" do \\
Estado/Governo
\end{tabular} & $\begin{array}{l}\text { Liberalização com liberdade } \\
\text { dos mercados. Regulação do Estado em } \\
\text { função do Mercado (e suas "falhas") }\end{array}$ \\
\hline $\begin{array}{l}\text { Sociedade } \\
\text { [(des)igualdades sociais } \\
\text { e extra-econômicas] }\end{array}$ & $\begin{array}{l}\text { Espontâneos e auto- } \\
\text { regulados pelos mercados }\end{array}$ & $\begin{array}{l}\text { Induzidos via quase- } \\
\text { mercados, regulados pelo Estado }\end{array}$ \\
\hline \begin{tabular}{l}
\multicolumn{1}{c}{ Raízes } \\
Ideológicas (pensamento \\
neoclássico)
\end{tabular} & $\begin{array}{l}\text { Ortodoxa } \\
\text { Escolas Anglo- } \\
\text { Americanas como referência-chave } \\
\text { "Fundamentalismo de Mercado": } \\
\text { perspectivar ultraneoliberal } \\
\text { leisseferista (laissez-faire) }\end{array}$ & $\begin{array}{l}\text { Heterodoxa } \\
\text { Autríacos/Ordoliberais } \\
\text { (alemães) / Economia Social de } \\
\text { Mercado (ESM) como referências-chave } \\
\text { "O Mercado é fundamental": } \\
\text { perspectiva proneoliberal anti-laissez- } \\
\text { faire }\end{array}$ \\
\hline $\begin{array}{l}\text { Teorias } \\
\text { Econômicas } \\
\text { Organizações }\end{array}$ & $\begin{array}{l}\text { Teorias clássicas e } \\
\text { neoclássica, Teorias de transição: } \\
\text { teoria da firma e Teoria dos custos } \\
\text { de transação }\end{array}$ & $\begin{array}{l}\text { Economia do conhecimento, } \\
\text { inovação e empreendedorismo; } \\
\text { generalização da forma empresa de } \\
\text { organizar }\end{array}$ \\
\hline
\end{tabular}

Fonte: tradução livre de Puello-Socarrás (2013a, p. 35-6); Smith (1776); Marshall (1898); Demsetz (1997); Coase (1937); Williamson (1985); Schumpeter (1942); Grant (1996). 
Generalização da forma empresa expressa na política federal de cultura- um experimento da renovação do neoliberalismo| Patricia Tometich - Rosimeri Carvalho - Rodrigo Gameiro Guimarães

Essa renovação foi construída a partir de críticas internas dos neoliberais, e não questiona elementos basilares, como as teses pró-mercado (PUELLO-SOCARRÁS, 2013). Nesse discurso do neoliberalismo renovado há indícios do abandono da centralidade da teoria neoclássica angloamericana e o princípio antropológico do homo economicus para privilegiar referentes austríacos de homo redemptoris (homem empreendedor) (PUELLOSOCARRÁS, 2010). Para os austríacos "o econômico" é baseado no paradigma da complexidade com referência à dinâmica presente nos processos gerais da ação humana, considerada no todo, não como segmento isolado, como para os americanos. Esses consideram o indivíduo como puramente calculador (homo economicus) ao contrário do homem empreendedor ou empresário criativo (homo redemptoris) dos austríacos (PUELLO-SOCARRÁS, 2010).

A esse movimento teórico operado no neoliberalismo, identificamos um paralelo com as teorias econômicas das organizações. $\mathrm{Na}$ visão econômica clássica, as firmas eram consideras como um agente especializado na produção de excedentes com valor de troca (SMITH, 1776; RICARDO, 1867). A firma era vista apenas como a organização dos fatores capital, trabalho e insumos para a entrega de bens e serviços ao mercado (BARNEY; HESTERLY, 2004). A base dos sistemas econômicos é a troca, que para Adam Smith seria a origem da divisão do trabalho, que possibilitava o aumento da produção, logo dos excedentes e geração de riqueza. Considerando que essa produção tem custos, e que o mercado determina os valores de troca, é necessário pensar na transação comercial, reflexões que se iniciam na perspectiva neoclássica.

$\mathrm{Na}$ abordagem neoclássica, as firmas eram vistas como uma função de produção, em que os preços são regulados segundo a lei de oferta e demanda (MARSHAL, 1898). As atenções se voltam para o preço, que refletiria um possivel equilíbrio no mercado. Demsetz (1997) estabeleceu que os mercados funcionariam sem custos; que os preços e a tecnologia utilizada seriam do conhecimento de todos os interessados; e que os donos das firmas manteriam controle eficaz sobre seus ativos. Na medida em que o sistema 
Generalização da forma empresa expressa na política federal de cultura- um experimento da renovação do neoliberalismo| Patricia Tometich - Rosimeri Carvalho - Rodrigo Gameiro Guimarães

econômico se modificava as limitações da teoria foram sendo percebidas - o mercado não funcionava gratuitamente, pois há um custo para a realização das trocas. Os limites explicativos da teoria neoclássica levaram ao desenvolvimento da abordagem dos custos envolvidos na sua operação (COASE, 1937; WILLIAMSON, 1985), o que constituiu as bases para percepção do empreendedor como figura central na tomada as decisões desses custos, e na criação de alternativas de gestão e de novos produtos (coordenador-empreendedor).

Coase (1937) foi quem primeiro apontou os custos nas relações comerciais entre os agentes econômicos (market costs). Ele discutiu o motivo do surgimento das firmas, propondo que estas se justificam quando o custo de fabricar for inferior ao de obter no mercado (COASE, 1937). Williamson (1996) questiona os limites do trabalho de Coase (1937) para compreender questões relativas ao tamanho, à forma e aos propósitos atendidos pelas corporações. Este autor defende a economia dos custos de transação (ECT) como uma perspectiva interdisciplinar que enfatiza a importância do organizar e destaca os mecanismos de governança como formas de contribuir com os resultados econômicos. Nesta visão, há duas formas de governança: mercado e hierarquia. As formas hierárquicas distinguem-se pelo controle direto de um terceiro (o administrador), com a responsabilidade e o direito de distribuir informações e resolver conflitos (BARNEY; HESTERLY, 2004).

Além do foco nas transações e formas de governança, os recursos das firmas explicariam o seu desempenho (PENROSE, 1959; WERNERFELT, 1984). Quanto mais específicos e dificeis de serem imitados, tais recursos poderiam garantir que as firmas acumulassem rendimentos com seus produtos. Permanece a questão do organizar, no sentido de reduzir custos de transação e de proteger o conhecimento. Já Nelson e Winter (1982) desenvolveram uma perspectiva evolucionária das firmas, considerando que elas possuem capacidades e regras internas que se modificam com o passar do tempo, como resultado dos esforços contínuos para a solução de 
Generalização da forma empresa expressa na política federal de cultura- um experimento da renovação do neoliberalismo| Patricia Tometich - Rosimeri Carvalho - Rodrigo Gameiro Guimarães

problemas e da seleção operada pelo mercado. Outros estudaram relações de alianças entre firmas formadas pelo reconhecimento de limitações competitivas e falta de determinados ativos (DYER; SINGH, 1998).

Partindo de uma abordagem da estratégia na relação entre as firmas, Grant (1996) fundou a teoria baseada no conhecimento. O conhecimento e a criatividade são compreendidos como algo que está dentro dos indivíduos, e a firma seria o agente que o aplica, mas não o "cria" - se utiliza de mecanismos de coordenação para integrar o conhecimento especializado das pessoas. O conhecimento passa a ser visto como transferivel; assimilável; com capacidade de agregação e de especialização em aquisição de mais conhecimento (GRANT, 1996). O conhecimento específico depende de um empreendedor visionário que crie as condições para que seja transformado em inovação. A inovação é abordada, por Schumpeter (1942), como relacionada à habilidade do empreendedor em ser capaz de modificar os padrões de produção da indústria com a criação ou invenção de novas tecnologias para a produção de bens e serviços; ou ainda, a possibilidade de produção de bens e de serviços que já são conhecidos ser realizada por diferentes formas, gerando produtos com valor reconhecido no mercado.

Schumpeter (1942) associou o empreendedor com a inovação e como responsável pelo desenvolvimento econômico. Outros autores relacionam o empreendedorismo a aspectos mais amplos. Apoiado no conceito de ação humana de Mises, Kirzner (1986) destacava a capacidade do empreendedor para detectar oportunidades de negócio, mas não apenas pelo cálculo economicista/maximizador. Para Mises (2010, p. 35) a ação humana envolve propósito, "é a significativa resposta do ego aos estímulos e às condições de seu meio ambiente; é o ajustamento consciente ao estado do universo que lhe determina a vida". Ainda que esta perspectiva destaque que as decisões dos indivíduos não são tomadas apenas por cálculos econômicos, é evidente que a interpretação do universo que permite a visão de oportunidades de negócio se liga ao desenvolvimento econômico, considerando, inclusive, que o trabalho de Kirzner (1986) trata de competição e atividade empresarial tendo entre seus argumentos que o "verdadeiro" papel do empresário na 
Generalização da forma empresa expressa na política federal de cultura- um experimento da renovação do neoliberalismo| Patricia Tometich - Rosimeri Carvalho - Rodrigo Gameiro Guimarães

economia de mercado e na competição vinha sendo negligenciado, criticando as ideias de Schumpeter.

Tanto Hayek quanto Kirzner e Mises divergiram de Schumpeter quanto à natureza do empresário e da atividade empreendedora. Enquanto Schumpeter (1982) atribui a ruptura no fluxo circular da economia (equilíbrio) à atividade do empresário, Kirzner (1986) afirma que a atividade do empresário seria um fator que leva ao equilíbrio do mercado.

Há uma estreita relação entre a economia do conhecimento e o empreendedorismo, no sentido de que nas diferentes abordagens há valorização de certo tipo (especial) de conhecimento. Hayek refletiu sobre a questão do uso do conhecimento, destacando que o problema econômico da sociedade passaria longe da questão da alocação ótima de recursos, pois as informações necessárias para as decisões econômicas estariam dispersas: "é um problema da utilização de conhecimento que não é dado a ninguém em sua totalidade" (HAYEK, 1945, p. 520).

Grant (1996) postula que o conhecimento está nos indivíduos e um empreendedor visionário é capaz de organizar fatores de produção para a aplicação de tal conhecimento; para Schumpeter (1942) o empreendedor é quem modifica os padrões de produção da indústria com uma criação ou invenção; já Mises (2010) destaca a ação humana consciente e com propósito. Podemos afirmar que também o empreendedor é dotado de conhecimento e habilidades que envolvem a organização e a geração de valor. Um indivíduo pode ser o responsável pela organização e geração de valor reconhecido pelo mercado (inovação), seja como o criador/fundador de uma organização, ou o organizador de um negócio que dependa de seu próprio conhecimento, criatividade e recursos.

Nesse percurso teórico, verifica-se como a criatividade passou a ser vista como recurso essencial para êxito nas transações no mercado. A firma e o empreendedor constituem-se os agentes centrais na integração do conhecimento dos indivíduos para produzir valor. Ainda que o conhecimento e a criatividade estivessem contidos nas explicações econômicas 
Generalização da forma empresa expressa na política federal de cultura- um experimento da renovação do neoliberalismo| Patricia Tometich - Rosimeri Carvalho - Rodrigo Gameiro Guimarães

neoclássicas, as novas abordagens atribuem centralidade a esses elementos. Sem questionar os pressupostos fundamentais das teorias econômicas dominantes, o foco dessas teorias desloca-se. Na visão clássica a troca, divisão do trabalho e concorrência eram centrais, na visão neoclássica o mercado (aspecto central do neoliberalismo) e seus mecanismos; com a teoria da firma, a organização ganha centralidade, sem subjugar o mercado na sua função de regular as trocas, de selecionar as firmas ou de definir o que é mais vantagem nas relações de troca, já na economia do conhecimento, essa vantagem pode ser obtida pela capacidade da firma de transformar conhecimento em mercadorias com um diferencial de dificil reprodução. Ainda que a explicação última seja como as firmas sobrevivem ou prosperam no mercado, enfatiza-se, nas pesquisas, as atividades internas, o conhecimento individual, a inovação e o empreendedorismo como aspectos-chave na geração de riqueza.

Não queremos dizer que essa abordagem é nova, pois vemos que a ênfase no conceito de empresário-empreendedor é historicamente arraigada no pensamento econômico liberal e que permanece no neoliberalismo, mas teve a importância eclipsada pelo conceito de homo economicus. A origem da teoria do empreendimento pode ser encontrada nos fisiocratas do século XVIII (Cantillon), nas quais o empresário é visto como uma pessoa empreendedora, toma iniciativa, está propício a riscos e incerteza frente aos beneficios, e combina fatores de produção sob sua responsabilidade (PUELLO-SOCARRÁS, 2010). Essa ênfase no empreendedor é destacada nas mais recentes teorias econômicas das organizações que vem ganhando força neste campo, o que reforça a ideia da relação entre tais teorias e a renovação do neoliberalismo.

Durante o século XX, o conceito de empreendedor vem sendo considerado como chave de interpretação do fenômeno econômico. Empresário/Empreendedor surgem como exigência epistemológica (ideológica e política) para explicar o capitalismo avançado, pois o homem empreendedor como fonte de seus próprios ganhos é um ser social e econômico complexo. Os austriacos anteciparam o estado de coisas do 
Generalização da forma empresa expressa na política federal de cultura- um experimento da renovação do neoliberalismo| Patricia Tometich - Rosimeri Carvalho - Rodrigo Gameiro Guimarães

presente, situaram o homem empreendedor como princípio antropológico por excelência do ser humano e viram no empreendimento a força ontológica constitutiva do processo de mercado (PUELLO-SOCARRÁS, 2010).

$\mathrm{O}$ homem empreendedor reforça o individualismo típico do neoliberalismo. O mercado não é somente espaço de intercâmbio e transações de bens e serviços individuais, mas um complexo institucional de oportunidade de criação, descobrimento, competência e ajuste no campo da interação social. Essa definição de mercado para os austriacos visa superar a definição da relação econômica como mero intercâmbio da ortodoxia neoclássica anglomericana, reconceitualizando Economia e econômico como algo mais amplo, integral e profundo (PUELLO-SOCARRÁS, 2010).

A teoria do empreendedor e do empreendimento pode ser resumida nas premissas: 1 empreendimento é uma iniciativa da qual não se tem certeza, nem se pode predizer um resultado futuro; 2 empreendedor é alguém com habilidade e confiança suprema de prever o futuro incerto e desconhecido; 3 o processo do empreendimento busca alcançar um estado futuro mediante sua intervenção e a criação de uma visão de futuro deriva do curso da ação identificada pelo agente-empreendedor; 4 empreendedor está sempre em alerta às oportunidades que não são percebidas no mercado. Sua ação frente à incerteza é a causa dos ganhos entendidos como excesso de retorno, e a inovação é sua função por excelência. 5 O empreendedor guia a produção social assumindo a função de coordenar a divisão de trabalho através da criação de uma empresa, ele é a forca motriz na sociedade de mercado (PUELLO-SOCARRÁS, 2010).

Observando o trabalho de Puello-Socarrás (2010) é possivel compreender que o empreendedor é colocado em destaque por ser o criador das soluções para os problemas sociais que envolvem a organização de fatores em uma forma específica - a forma empresa. Essa generalização da forma empresa já fora apontada por Foucault (2008) em seus estudos sobre o neoliberalismo. Foucault (2008, p. 179) reconheceu na "política de sociedade" a "formalização da sociedade com base no modelo da empresa", 
Generalização da forma empresa expressa na política federal de cultura- um experimento da renovação do neoliberalismo| Patricia Tometich - Rosimeri Carvalho - Rodrigo Gameiro Guimarães

uma "sociedade empresarial" em que quanto maior a liberdade juridicamente formalizada para que os indivíduos se comportem "como querem na forma da livre empresa, mais se desenvolvem na sociedade essas formas múltiplas e dinâmicas da unidade 'empresa"' (FOUCAULT, 2008, p. 240).

Entendemos que essas transformações nas referências teóricas do neoliberalismo, relacionadas às mudanças na economia, estão imbricadas com implicações práticas e políticas, uma delas foi aguçar a mercantilização de aspectos da vida, não somente pelo modelo de privatização e controle das grandes empresas, mas por meio de pequenas iniciativas individuais.

No Brasil, desde a reforma administrativa do governo militar de 1967 encontramos uma redefinição das atividades e do modelo de gestão do Estado em relação ao setor privado, quando houve a divisão da administração pública em direta e indireta (BARBOSA; SILVA, 2010). Aconteceram privatizações na década de 1980, mas foi em 1995 (governo Fernando Henrique Cardoso) que as privatizações se intensificaram e que o neoliberalismo ganhou força, com a criação de um ministério para a reforma do aparelho de estado, que teve a ambição de promover mudança de cultura no serviço público, inspirada na administração privada e no empreendedorismo (ANDREWS, 2010).

A entrada de um governo autoproclamado progressista, em 2003, não alterou o cerne da orientação neoliberal. Indícios dessa continuidade são a reforma da previdência dos servidores públicos, em 2003 (SOUZA, 2006); a criação das parcerias público-privadas em 2004 (SANTANA; RODRIGUES, 2006); e a criação da Empresa Brasileira de Serviços Hospitalares em 2011 (PAIVA; PEREIRA; JUSTINO, 2013). Aqui nos interessa como o neoliberalismo se expressa nas políticas públicas federais de cultura, o que abordaremos na próxima seção.

\section{Histórico Políticas Federais de Cultura (PFC) no Brasil e a convergência com a renovação do neoliberalismo}

No Brasil há dois marcos norteadores da PFC: a promulgação da Constituição Federal de 1988, com dois artigos dedicados à cultura, referentes aos direitos culturais e ao patrimônio cultural; e a criação de um 
Generalização da forma empresa expressa na política federal de cultura- um experimento da renovação do neoliberalismol Patricia Tometich - Rosimeri Carvalho - Rodrigo Gameiro Guimarães

ministério para a área no início do período de redemocratização política, em 1985. Uma das primeiras ações do Ministério foi, em 1986, a operacionalização da primeira Lei Federal de Incentivo Fiscal à Cultura, marco na relação do Estado com a comunidade artística e sociedade (GAMEIRO; CARVALHO, 2010). Seu propósito era atrair investimentos privados para o financiamento da cultura mediante isenção fiscal. Apesar da comissão indicada pelo Governo, composta por membros da administração pública, julgar os projetos culturais, a decisão final de aplicação dos recursos era das empresas.

A $1^{\text {a }}$ lei de incentivo foi defendida pelo Ministro da Cultura como uma contribuição para o desenvolvimento cultural do país, destacando seu espírito descentralizador, pois transferia à sociedade a iniciativa dos projetos, mobilização dos recursos e controle da sua aplicação. Tal lei possibilitaria a eliminação de custos administrativos e superação da desigualdade característica das sociedades de desenvolvimento retardado, segundo FURTADO (2012, p.84-85). Ainda que reconheçamos a ênfase na liberdade/independência da produção cultural perante um Estado governado por uma ditadura militar que atuou como censora e financiadora daquilo que os tecnocratas definiam como cultura, não podemos deixar de considerar que essa PFC carregava uma orientação neoliberal de desregular a atuação do Estado na cultura e promover a criação de um mercado cultural sustentado por recursos públicos, mas gerenciado pelas empresas.

$\mathrm{Na}$ década de 1990, a lei de incentivo foi aperfeiçoada e os governos realizaram ampla difusão de seu uso, destacando a cultura como bom negócio. Surgem institutos e fundações culturais mantidos por empresas privadas, que substituíam o Estado em funções essenciais de fomento (MOISÉS, 2001). Nesse período as PFC ficaram resumidas à lei de incentivo à cultura, que serviu para financiar as grandes produções de artistas nacionais com acesso aos departamentos de marketing de empresas que utilizavam recurso público para financiar campanhas publicitárias por meio de eventos ou organizações culturais. Esse modelo foi copiado por 
Generalização da forma empresa expressa na política federal de cultura- um experimento da renovação do neoliberalismo| Patricia Tometich - Rosimeri Carvalho - Rodrigo Gameiro Guimarães

secretarias de cultura dos estados e municípios. No entanto, Olivieri (2002) identificou alguns problemas: concentração dos recursos no Sul e Sudeste do país e no Eixo Rio-São Paulo; e a obtenção de recursos por menos de um terço dos projetos aprovados. O problema desta política, constatado por muitos analistas, reside na decisão privada sobre a utilização de recursos públicos. Ao invés de combater as desigualdades regionais, há a criação de novas, pois os recursos são destinados a algumas manifestações culturais, selecionadas em função de interesse mercadológico, e não pelo interesse público ou importância histórica de um determinado evento.

Por isso, consideramos que as leis de incentivo, ainda que na origem se justificassem pela democratização da intervenção estatal e redução das desigualdades, estavam alinhadas com o ideário NEOLIBERAL - de minimização da direção do mercado cultural (velho neoliberalismo) pelo Estado, ainda que financiada com recursos públicos. Esse processo foi ganhando força na década de 1990, quando se implementou a reforma gerencial da administração pública no Brasil com orientação para redução do tamanho do Estado: operada por privatizações, criação de agências reguladoras, demissões, mudanças de regime de trabalho e disseminação de práticas de gestão empresarial e do empreendedorismo na gestão pública (PAES DE PAULA, 2005). Começa a ser gestado o desenho de um Estado regulador (novo neoliberalismo), apesar de fornecedor de recursos para o nascente mercado cultural.

Essa orientação de governo e as consequências práticas das PFC foram alvo de críticas e articulação de artistas e movimentos culturais. O eco dessas críticas se concretizou politicamente no plano de governo da coligação de oposição que disputava o governo federal em 2002, liderada pelo Partido dos Trabalhadores (PT). Inspirada nos governos sub-nacionais do PT e na articulação com os movimentos, propunha-se ampliar o papel do Estado no setor e a participação da sociedade nas decisões do governo. As PFC seriam orientadas pela visão ampliada da cultura, baseada no conceito antropológico, pela sua democratização, e pela democratização da gestão (GUIMARÃES, 2007). O novo governo orientou as politicas a partir de um 
Generalização da forma empresa expressa na política federal de cultura- um experimento da renovação do neoliberalismo| Patricia Tometich - Rosimeri Carvalho - Rodrigo Gameiro Guimarães

conceito abrangente de cultura, baseado em três dimensões: simbólica (estética e antropológica); cidadã; e econômica (BRASIL, 2006a).

Essa renovação nas PFC foi influenciada pelo contexto e movimentos culturais locais, mas não desconsideramos a relevância das discussões e dos documentos das organizações multilaterais, como a UNESCO. Esses documentos alertam para ampliação global dos mercados culturais e dos possiveis riscos de padronização cultural e foram construídos junto a redes de organizações em defesa da promoção da identidade e diversidade cultural (ALVES, 2010). O ministério da cultura brasileiro liderou a discussão de inclusão de categorias como diversidade nas políticas públicas para culturas populares e de patrimônio imaterial; e indústria da criatividade e desenvolvimento nas políticas em geral. Tais discussões guiaram a formulação de programas visando criar mercados, emprego e renda para produtores, artistas e técnicos ligados às culturas populares (ALVES, 2010).

Um exemplo específico de política com essa orientação é o Programa Cultura Viva (PCV). Criado em 2004, o PCV teve o propósito de potencializar as expressões culturais populares que eram marginalizadas ou desconhecidas. O projeto consistia em dar suporte financeiro à produção cultural de "populações de baixa renda; estudantes da rede básica de ensino; comunidades indigenas, rurais e quilombolas; agentes culturais, artistas, professores e militantes que desenvolvem ações no combate à exclusão social e cultural” (BRASIL, 2004, p. 47). O PCV pretendia oferecer uma alternativa ao modelo de financiamento via renúncia fiscal e constituir um modelo de gestão flexivel capaz de dialogar com os agentes culturais, sem impor uma proposta pré-determinada (TURINO, 2009). O programa preconizava a formação de uma rede dos Pontos de cultura para o intercâmbio de informações, experiências e realizações, propiciando trocas sem relações hierárquicas. Contudo, essa proposta foi deslocada pelo rumo político do governo, de modo que o PCV perdeu relevância no MINC (CARVALHO, GAMEIRO e DOURADO, 2013). 
Generalização da forma empresa expressa na política federal de cultura- um experimento da renovação do neoliberalismo| Patricia Tometich - Rosimeri Carvalho - Rodrigo Gameiro Guimarães

Após a reeleição do Presidente Lula, em 2007, há uma reorientação nas PFC com ênfase na cultura como setor econômico que representa importante alternativa do projeto de desenvolvimento nacional. Ao analisar o discurso dos dois programas de governo federal da coligação liderada pelo PT, Gameiro e Carvalho (2010, p. 16) identificam no $1^{\circ}$ programa de governo, ainda que de forma secundária, a preocupação de explorar a riqueza e diversidade cultural do Brasil como um ativo econômico para resolver os problemas internos do país. No $2^{\circ}$ plano destaca-se a preocupação estratégica de conectar cultura com o projeto de desenvolvimento nacional. As leis de incentivo seguiram com o maior montante do orçamento público da cultura no Brasil. Em ambos não é somente a indústria cultural de massa, com produtos padronizados, que viabilizaria a exploração da dimensão econômica da cultura e seu potencial de desenvolvimento. O novo foco das políticas é no consumo cultural de nicho, na diversidade, nos produtos e experiências autênticas, singulares e customizadas. A diversidade cultural é compreendida como um ativo a ser exportado, o que seria viabilizado pela descentralização da produção cultural em micro e pequenos empreendimentos.

Analisamos que, apesar do arejamento conceitual e programático das PFC e do novo foco nas manifestações populares e marginais, a cultura continuou figurando como um bem que poderia ser mercantilizado e tornarse fonte de emprego e renda. Antes as políticas de mínima intervenção do Estado (neoliberalismo), como as leis de incentivo, direcionavam os recursos para artistas e manifestações consagrados e para a indústria cultural de massa. No novo modelo o Estado atuou como incentivador direto das manifestações culturais marginais (transição para novo neoliberalismo), procurando corrigir as distorções geradas pelo modelo de "livre mercado" das leis de incentivo, e promover a defesa da diversidade, do patrimônio imaterial e da criatividade. Ainda que consideremos esse foco democratizante do PCV, não podemos deixar de reconhecer que o programa perde força e espaço dentro do Ministério, e a diversidade, o patrimônio imaterial e a criatividade ganham um novo guardião: a Secretaria de Economia Criativa. 
Generalização da forma empresa expressa na política federal de cultura- um experimento da renovação do neoliberalismo| Patricia Tometich - Rosimeri Carvalho - Rodrigo Gameiro Guimarães

Para entender melhor o propósito dessa secretaria, fomos buscar o significado e como surge a categoria que lhe empresta o nome. Em 1998, surgiu, pela $1^{\mathrm{a}}$ vez, o termo Indústria Criativa num documento do Ministério da Cultura, Mídia e Esporte Britânico que a define como "Os setores que têm sua origem na criatividade, na perícia e no talento individuais e que possuem um potencial para criação de riqueza e empregos através da geração e da exploração de propriedade intelectual". Em 2001, dois trabalhos trouxeram novas perspectivas sobre o tema: um agregou uma visão empresarial baseada em conceitos mercadológicos de propriedade intelectual, em que patentes, marcas e direitos autorais forneciam principios para transformação da criatividade em produto; e o outro focou nos profissionais que trabalhavam com processos criativos e lançou luz sobre uma nova classe de trabalhadores (FIRJAN, 2012).

A EC está ligada a ideia de relação entre economia, informação e conhecimento (FLORIDA, 2011). Citando Peter Drucker, que apresenta como um visionário, Florida (2011) afirma que os meios de produção já não são os recursos naturais, nem o capital - "daqui para frente o recurso econômico básico é o conhecimento" (FLORIDA, 2011, p. 44). Conhecimento específico nas variadas artes, no entretenimento, na capacidade de proporcionar experiências e com a habilidade de ser criativo. Vemos nessa construção que o capital é desconsiderado como meio de produção, como se fosse possível um "empreendedor" criativo registrar sua marca ou patente sem estar munido de capital. Ao mudar de parágrafo, Florida (2011) imediatamente cai em contradição com relação a esta afirmação, pois mostra os crescentes investimentos em pesquisa e desenvolvimento (que classifica como em criatividade) nos Estados Unidos a partir da década de 1950 - uma variação positiva de $800 \%$ nos gastos com criatividade no período entre 1953 e 2000 .

No Brasil, as discussões sobre EC iniciam em 2004, quando foi realizado o encontro da Conferência Ministerial UNCTAD (REIS, 2008). Nesse encontro, as indústrias criativas foram pautadas na agenda internacional da economia e desenvolvimento. Há discussões sobre: serviços criativos no 
Generalização da forma empresa expressa na política federal de cultura- um experimento da renovação do neoliberalismo| Patricia Tometich - Rosimeri Carvalho - Rodrigo Gameiro Guimarães

Acordo Geral sobre o Comércio de Serviços que culminaram na direção de liberalizar o comércio de serviços; acordos para proteção dos direitos de propriedade intelectual que orientam as questões relacionadas à arrecadação para serem tratadas nacionalmente e na Organização Mundial de Propriedade Intelectual (SANTOS-DUISENBERG, 2008). Outros debates incluem a área educacional e formação dos profissionais, a requalificação urbana, a valoração intangivel da cultura por parte das instituições financeiras, o reposicionamento do papel da cultura na estratégia socioeconômica e a revisão da estrutura econômica pela inclusão de novos modelos de negócio (REIS, 2008).

A EC é uma categoria permeada por diferentes significados, alguns incluem as artes e entretenimento, outros voltados a gerar direitos de propriedade intelectual. É possível encontrar definições que unem cultura e tecnologias (REIS, 2008). Enquanto a economia da cultura propõe a valorização da autenticidade e do intangivel cultural como uma promessa aos países em desenvolvimento, no campo da EC reconhece-se a importância da tecnologia no contexto global e da criatividade na constituição de "[...] novos modelos de negócios, processos organizacionais e uma arquitetura institucional que galvaniza setores e agentes econômicos e sociais." (REIS, 2008, p. 23).

Em termos das PFC, o Ministério buscou guiar a Secretaria pelas necessidades e condições do Brasil e formulou uma definição norteadora para suas políticas, partindo de fundamentos da inclusão social, da sustentabilidade, da inovação e da diversidade. A definição considera como setores criativos "todos aqueles cujas atividades produtivas têm como processo principal um ato criativo gerador de valor simbólico, elemento central da formação do preço, e que resulta em produção de riqueza cultural e econômica" (MINC, 2011, p. 22). Outro aspecto norteador da EC é a vinculação entre criatividade e desenvolvimento. A diversidade cultural brasileira e o potencial criativo do país são definidos como um recurso essencial para o desenvolvimento econômico. No plano da secretaria (20114), há a defesa de que o desenvolvimento de uma sociedade marcada pela 
Generalização da forma empresa expressa na política federal de cultura- um experimento da renovação do neoliberalismo| Patricia Tometich - Rosimeri Carvalho - Rodrigo Gameiro Guimarães

desigualdade das estruturas sociais e concentradora passa por uma superação do controle dos bens de produção da criatividade artística, científica e tecnológica operado por grupos privados. A atuação da secretaria tem como objetivo ampliar a transversalidade das politicas e a estratégia de afirmação da importância das politicas públicas de cultura para o desenvolvimento (MINC, 2011). No plano da secretaria de economia criativa, de 32 ações, 10 são referentes ao fomento ao empreendedorismo, considerado um dos desafios da EC brasileira.

Apesar das divergentes definições, alguns pesquisadores consideram que a EC não pode ser reduzida a um apanhado de politicas voltadas a setores econômicos de ponta, mas talvez o marco de um novo ciclo econômico, em escala global. É um novo paradigma, em que a cultura está na essência e o intangivel é o aspecto relevante na produção, a tecnologia é o veículo de propulsão para a produção, distribuição e/ou acesso aos bens e serviços e a unicidade da produção e a organização dos mercados é em rede, pautados em parcerias entre agentes sociais e econômicos, que configuramse como "[...] traços característicos desse modelo que tem como pressuposto de sustentabilidade a melhoria do bem-estar e a inclusão socioeconômica." (REIS, 2008, p. 47-8). Por outro lado, consideramos que essa categoria se estabelece pela ideia/crença de que surgiu recentemente e está em crescimento um tipo de economia caracterizada pela abundância e fundada na ideia de que a criatividade como principal insumo e resultado não se esgota. Daí a justificativa de que outras teorias econômicas seriam mais adequadas para explicar esse fenômeno.

O Estado brasileiro desenha a Economia Criativa como uma solução para a questão da falta de emprego, e considera que esta seria uma maneira de produzir valor sem degradar o ambiente. Ao discorrer sobre empreendedorismo aplicado ao contexto da Economia Criativa, Howkins (2013, p. 156) declara que os empreendedores "usam a criatividade para liberar a riqueza que se encontra dentro deles”. É uma atividade associada 
Generalização da forma empresa expressa na política federal de cultura- um experimento da renovação do neoliberalismo| Patricia Tometich - Rosimeri Carvalho - Rodrigo Gameiro Guimarães

ao enriquecimento, que desconsidera a desigualdade de condições de acesso aos recursos que permitiriam tal "liberação de riqueza interna".

A EC está ligada ao movimento que ficou conhecido como regime pósfordista, sendo ele o portador das ideias-força que a fizeram emergir (PIRES, 2009). Em tal regime, as relações de trabalho são modificadas e encontramse na literatura termos como desregulamentação, flexibilização, trabalho atípico, precarização do trabalho. Trabalho atípico é aquele em que não existe regime constante e nem exclusividade na prestação do serviço; não há tempos e lugares determinados para o trabalho; não há diversidade de posição entre quem trabalha com contrato ou informalmente (VASAPOLLO, 2005).

Os trabalhadores da Economia Criativa exercem atividades que, em sua maioria, nunca contaram com regulamentação ou garantias como um contrato por tempo indeterminado. Ao estabelecer o que chamou de "princípios da administração criativa", Howkins (2013, p.161) argumenta a necessidade da "pessoa just in time": seriam aquelas pessoas que "estejam disponiveis de uma hora para a outra" (...) "que são contratadas apenas quando e onde são desejadas". Quando os autores indicam essa flexibilidade como uma característica do empreendedor que pretende ter sucesso no campo da criatividade, estão naturalizando a exploração da criatividade pelo mercado, num contexto em que as grandes corporações ditam quando e onde os novos "empreendedores" vão vender seus produtos culturais. As relações prescritas pelo ideário do novo neoliberalismo são entre pessoas jurídicas, incentivando, como já percebera Foucault (2008) a criação de pequenas empresas complementares - empresas que possam suprir demandas pontuais, "just-in-time" no mercado da criatividade.

Ao analisarmos o reposicionamento no campo das teorias econômicas das organizações, percebemos que o foco vai saindo das relações entre os agentes para se voltar para as atividades internas, e o conhecimento vai sendo cada vez mais reconhecido como aspecto decisivo para a geração de riqueza. Não por coincidência, é na mesma direção que se verifica o reposicionamento das teorias econômicas dominantes que guiam as politicas 
Generalização da forma empresa expressa na política federal de cultura- um experimento da renovação do neoliberalismol Patricia Tometich - Rosimeri Carvalho - Rodrigo Gameiro Guimarães

econômicas nacionais e globais e representam a base da renovação ideológica do neoliberalismo, antes pautadas em princípios neoclássicos, e agora cada vez mais guiadas por principios do empreendedorismo e da economia da inovação, tendo a forma empresa de organização como base para o desenvolvimento social. Esses mesmos princípios estão guiando discussões sobre alternativas de_desenvolvimento econômico e regulamentação do comércio internacional no campo da propriedade intelectual e patentes, assim como influenciando a formulação de politicas em áreas sociais como educação (profissional e inovadora) e cultura (patrimônio imaterial).

\section{Considerações finais}

Nesse novo cenário econômico e ideológico, as atividades culturais adquirem um novo status e tornam-se um dos setores principais dessa "nova economia", já que o campo da cultura é, por excelência, o lócus humano da criatividade. Guiadas por essa categoria, as politicas federais de cultura focam as manifestações culturais populares não só pelos princípios da diversidade e sua proteção, mas vinculadas ao modelo econômico do mercado de nicho, em que o consumidor busca o singular e exótico. Essas manifestações populares, que até então eram desprezadas pelas politicas culturais, foram contempladas e integradas por meio da geração de renda que a inclusão no mercado poderia proporcionar. Para isso, essas organizações, pautadas no discurso programático do neoliberalismo e da economia criativa, se direcionam por estratégias de inovação, em que a manutenção da identidade cultural será guiada não mais por questões de alteridade ou tradição, mas por interesses da uma nova ordem econômica guiada pelo conhecimento e criatividade.

Quais as implicações dessas transformações nas políticas culturais para os movimentos culturais no Brasil? Lembremos que nossa nação se expressa culturalmente, sobretudo a partir de manifestações que não 
Generalização da forma empresa expressa na política federal de cultura- um experimento da renovação do neoliberalismo| Patricia Tometich - Rosimeri Carvalho - Rodrigo Gameiro Guimarães

possuem instituições formais para preservá-las, como ocorre nos países europeus.

Vemos um movimento em defesa no campo do resgate da história de grupos que foram inseridos na história oficial ou no máximo figuravam como figuras subalternas, como é o caso das manifestações afro-brasileiras e indígenas. Esse movimento de registro da história pela memória e da proteção desses grupos, via patrimônio imaterial, é fundamental para garantir no mínimo a existência dessas figuras marginais nas sociedades. No entanto, o que assistimos aliados a essas politicas que se preocupam com o registro da propriedade intelectual sobre saberes, fazeres e conhecimentos populares, inclusive que passaram a ser considerados bens comuns pelos governos nacionais e organismos internacionais, é que eles se tornam alvo de proteção via regulação política que visa submetê-los a fins notadamente econômicos. Tornando possivel a transformação dessas manifestações em organizações empresariais, seus artistas em empreendedores e suas produções em mercadorias que inclusive circulam internacionalmente.

Parece-nos clara a inspiração das politicas culturais federais e, especificamente, a ênfase dada à Economia Criativa, na formação históricodiscursiva do neoliberalismo, notadamente, pelo incentivo ao empreendedorismo e à generalização da forma empresa, em um contexto de desregulamentação das relações de trabalho. Ainda que ela não tenha acontecido pari passu com as mudanças nos países centrais onde o discurso neoliberal se desenvolveu anteriormente. Em que pese a dificuldade para a geração de empregos, e considerando que as pesquisas sobre a participação da economia da cultura no PIB brasileiro são animadoras (tendo em conta a informalidade característica das atividades culturais), a EC no Brasil nasce com a perspectiva de impulsionar o desenvolvimento, como opção de renda para uma parcela marginal da sociedade, que apesar de sua criatividade e da singularidade de seu fazer cultural não vinha tirando desse fazer o seu sustento.

Ainda que a política de EC esteja voltada para a promoção da diversidade e da inclusão social, sua forma de atuação se dá a partir do 
Generalização da forma empresa expressa na política federal de cultura- um experimento da renovação do neoliberalismo| Patricia Tometich - Rosimeri Carvalho - Rodrigo Gameiro Guimarães

financiamento de agentes dos setores considerados intensivos em criatividade. Esses agentes se tornariam então "empreendedores culturais" e estariam aptos a "ir ao mercado" oferecer os seus produtos. Ocorre que a cultura tornada mercadoria, sem que os novos "empreendedores culturais" tenham os recursos necessários para a ampla difusão de seus "produtos", corre o risco de ter o seu valor apropriado pela indústria cultural, pelo capital. De posse dos recursos financeiros e conhecendo o mercado global, estes "velhos" empreendedores têm condições de lucrar com a criatividade e a diversidade da cultura brasileira. É sabido que para a ampliação dos mercados existe a necessidade de recursos financeiros, sem os quais os pequenos produtores são explorados pelas grandes corporações.

Percebemos que a abordagem econômica das organizações foi, ao longo do tempo, voltando o olhar para o conhecimento específico e para a criatividade. Se num primeiro momento essas teorias apresentam a necessidade de uma organização específica para ordenar os fatores de produção e possibilitar a geração de valor a partir do conhecimento individual, há o reconhecimento que, da mesma forma, um indivíduo pode organizar os fatores necessários e empreender sozinho. Esse incentivo ao empreendedorismo, que analisamos nas politicas federais, mas que pode ser percebido em muitas outras políticas e ações, vem acompanhado de uma ênfase crescente dada pelas teorias econômicas ao papel do conhecimento, da inovação e do agente econômico empreendedor.

A análise das políticas de economia criativa nos indicou que essas políticas ilustram como o empreendedorismo é generalizado no âmbito das organizações e setores econômicos onde a criatividade é um recurso ou produto, pois define que todos podem ser empreendedores e, ao mesmo tempo, conjugando-se a renovação do neoliberalismo; por outro lado, elas abordam a ação econômica pela perspectiva da criatividade e do conhecimento que ainda escapavam ao controle da firma, por estar no indivíduo. 
Generalização da forma empresa expressa na política federal de cultura- um experimento da renovação do neoliberalismo| Patricia Tometich - Rosimeri Carvalho - Rodrigo Gameiro Guimarães

Em termos de limitações, este texto traz uma de ordem teórica, pois antes de aprofundar, procurou fazer uma primeira aproximação das transformações do neoliberalismo com as reformulações das teorias das organizações, sobretudo o enfoque econômico. A outra diz respeito ao objeto empírico, a Economia Criativa, e ao foco no plano das políticas e programas públicos, bem como a análise mais detida ao caso brasileiro, bem como a busca sobre o tema ter se restringido aos principais documentos escritos da área. Nesse sentido, deixamos como sugestão de pesquisa futura, o aprofundamento da discussão teórica sobre o neoliberalismo e a teoria das organizações e de uma pesquisa mais detalhada sobre as politicas, mas também da genealogia do conceito de economia criativa.

\section{Referências}

ANDREWS, C. Da década perdida à reforma gerencial: 1980-1998. In: ANDREWS, C.; BARIANI, E. (Orgs.). Administração pública no Brasil: breve história politica. São Paulo: UNIFESP, 2010. p. 85-118.

ALVES, E. P. M. A economia simbólica da cultura popular sertanejonordestina. 2009. 385 f. Tese (Doutorado) - Doutorado em Sociologia, Universidade de Brasília, UnB, Brasilia, 2009.

ALVES, E. P. M.. Diversidade cultural, patrimônio cultural imaterial e cultura popular: a Unesco e a construção de um universalismo global. Sociedade e Estado (UnB. Impresso), v. 25, p. 539-560, 2010.

ANDERSON, P. Balanço do Neoliberalismo. In: SADER, E.; GENTILI, P. (org.) Pós-neoliberalismo: as politicas sociais e o estado democrático. Paz e Terra, 2008. p.9-23.

BARBOSA e SILVA, L. A reforma administrativa de 1967. In: ANDREWS, C.; BARIANI, E. (Orgs.). Administração pública no Brasil: breve história política. SP: UNIFESP, 2010. p. 63-84.

BOTELHO, I. As dimensões da cultura e o lugar as politicas públicas. São Paulo em perspectiva, v.15, n.2, 2001.

BRESSER PEREIRA, L. C. A reforma gerencial do Estado de 1995. Rio de Janeiro: Revista de Administração Pública, v. 34, n. 4, p. 7-26, Jul./Ago. 2000 . 
Generalização da forma empresa expressa na política federal de cultura- um experimento da renovação do neoliberalismo| Patricia Tometich - Rosimeri Carvalho - Rodrigo Gameiro Guimarães

BRASIL. Ministério da Cultura. Cultura Viva: Programa Nacional de Cultura, Educação e Cidadania. Brasília: Ministério da Cultura, 2004.

CARVAlHO, C. A.; GAMEIRO, R.; DOURADO, D. C. P. Do PCV à economia da cultura: uma análise das politicas públicas de cultura dos governos progressistas. In: IV Seminário Internacional Politicas Culturais, 2013, Rio de Janeiro. Anais IV Seminário Internacional Politicas Culturais. Rio de Janeiro: Casa de Rui Barbosa, 2013. v.1 p.1-15.

COASE, R. The nature of the firm. Economica, v. 4, n. 16, p. 386-405, 1937.

DYER, J.; SINGH, H. The relational view: cooperative strategy and sources of interorganizational competitive advance. Academy of Manahement Review. v. 23, n.4, p.660-679, 1998.

FIRJAN. Federação das Indústrias do Estado do Rio de Janeiro. Mapeamento da Indústria Criativa no Brasil. Rio de Janeiro: FIRJAN, 2012. Disponível em: <http://www.firjan.org.br> Acesso em: maio de 2014.

FOUCAULT, Michel. A arqueologia do saber. Rio de Janeiro: Forense, 2005.

FOUCAULT, M. Nascimento da Biopolitica. Curso dado no Collège de France (1978-1979) São Paulo, Martins Fonte, 2008

FLORIDA, Richard. A Ascenção da classe criativa. Porto Alegre: L\&PM, 2011.

FURTADO, C. Ensaios sobre cultura e o Ministério da Cultura. Rio de Janeiro: Contraponto: Centro Internacional Celso Furtado, 2012.

GAMEIRO, R.; CARVALHO, C. A.. Estratégias Discursivas e Intenções (Des)veladas dos Programas e Politicas de Cultura dos Governos Lula. In: VI Encontro de Estudos Organizacionais-ENEO, 2010, Florianópolis. Anais do VI Encontro de Estudos Organizacionais da ANPAD. Rio de Janeiro: ANPAD, 2010. v. 1. p. 1-17.

GUimarães, Rodrigo Gameiro. No Campo das Politicas Públicas Culturais em Pernambuco, os Caranguejos com cérebro se organizam para desorganizar. 2007. 210 f. Dissertação (Mestre) - Curso de Administração, UFPE, Recife, 2007.

GRANT R. Toward a knowledge-based theory of the firm. Strategic Management Journal, v. 17, Winter Special Issue, p. 109-122, 1996.

HAYEK, F. von. The use of knowleadge in society. The American Economic Review, Vol. 35, No. 4, pp. 519-530, Sep., 1945). 
Generalização da forma empresa expressa na política federal de cultura- um experimento da renovação do neoliberalismo| Patricia Tometich - Rosimeri Carvalho - Rodrigo Gameiro Guimarães

HOWKINS, John. Economia Criativa - Como ganhar dinheiro com ideias criativas. São Paulo: M. Books, 2013

KIRZNER, I. M. Competição e Atividade empresarial. RJ, Instituto Liberal, 1986.

MARSHALL, A. Principles of economics. 4. ed. London: Macmillan, 820 p., 1898.

MINC. Plano da Secretaria de Economia Criativa - políticas, diretrizes e ações, 2011-2014. Brasília, Ministério da Cultura, 2011.

MISES, L. V. Ação Humana, um tratado de economia. SP: Instituto L von Mises, 2010.

MOISÉS, José Álvaro. Estrutura Institucional do Setor Cultural no Brasil. Cadernos do Nosso Tempo. Cultura e Democracia. RJ: FUNARTE, vol. 1, p. 13-55, 2001.

NELSON, R.R.; WINTER, S. An Evolutionary Theory of Economic Change. Cambridge (Ma), The Belknap Press of Harvard University Press. 1982.

OLIVIERI, C. G. O incentivo fiscal federal à cultura e o Fundo Nacional de Cultura como política cultural do Estado: usos da lei rouanet (1996-2000). 2002. 136f. Dissertação (mestrado) - Ciências da Comunicação, Universidade de São Paulo, 2002.

PAIVA, A. dos S.; PEREIRA, J. T. S.; JUSTINO, M. J. Políticas públicas de saúde e as ofensas do neoliberalismo: os limites da empresa brasileira de serviços hospitalares para os hospitais universitários brasileiros. VI Jornada de Politicas Públicas, agosto de 2013.

PAULA, A. P. P. de. Administração Pública Brasileira entre o Gerencialismo e a Gestão Social. Revista de Administração de Empresas, v.45, n.1, jan./mar, 2005, p.36-47.

PENROSE, E. The Theory of the Growth of the Firm. NY: Oxford, 1995, $272 \mathrm{p}$.

PIRES, Vladimir Sibylla. Ideias-força no pós-fordismo e a emergência da Economia Criativa. Liinc em Revista, v. 5, n. 2, setembro, 2009.

PUELLO-SOCARRÁS, JF. “¿Un Nuevo Neo-liberalismo? Emprendimiento y Nueva Administración de "lo público". Revista Administración \& Desarrollo (Bogotá: Escuela Superior de Administración Pública) No. 49, Primer Semestre. p. 7-39. 2008.

PUELLO-SOCARRÁS, JF. “Ocho tesis sobre el neoliberalismo (1973-2013)" In: Ramírez, Hernán, O neoliberalismo Sul-Americano em Clave 
Generalização da forma empresa expressa na política federal de cultura- um experimento da renovação do neoliberalismo| Patricia Tometich - Rosimeri Carvalho - Rodrigo Gameiro Guimarães

Transnacional: enraizamento, apogeu e crise. São Leopoldo: Oikos Unisinos, p. 13-57. 2013a.

PUELLO-SOCARRÁS, JF. "Breve historia del anti-neoliberalismo. Economía politica sudamericana y paradigmas de desarrollo en el siglo XXI". In: AA.VV., Anuario de Estudios Politicos Latinoamericanos, No. 1, Bogotá: Universidad Nacional de Colombia, Maestría en Estudios Políticos Latinoamericanos., p. 167-186. 2013b.

PUELLO-SOCARRÁS， JF y GUNTURIZ， A.. “¿Social-neoliberalismo? Organismos multilaterales, crisis global y programas de transferencia monetaria condicionada". Politica y Cultura (México: Universidad Autónoma Metropolitana - Xochimilco) No. 40, p. 29-54. 2013c.

REIS, ACF. Introdução. In REIS, A.C.F. Economia criativa como estratégia de desenvolvimento: uma visão dos países em desenvolvimento. SP: Itaú Cultural, 2008.

RICARDO, D. (1817). Principios de economia politica e tributação. SP: Abril Cultural, 1996.

RODRIGUES, M.S.; SILVA, R.C.. Empresarização e Modernidade: A Ideia de Empresa no Centro do Mundo. Revista Brasileira de Estudos Organizacionais, v. 6, p. 40-76, 2019a.

RODRIGUES, M.S.; SILVA, R.C.. Nova República, Novas Práticas: uma análise do processo de empresarização do ensino superior brasileiro (19902010). Farol - Revista de Estudos Organizacionais e Sociedade, v. 6, p. 176-218, 2019b.

RODRIGUES, M.S.; SILVA, R.C.. Empresarização no Figueirense Futebol Clube e no Sport Club Internacional. Gestão.Org, v. 4, p. 38-54, 2006.

SANTANA, G. D.; RODRIGUES JR., H. S. As parcerias público privadas: solução ou problema? Prismas: Direito, Política Pública e Mundial, v. 3, n. 1, p. 148-181, 2006.

SANTOS-DUISENBERG, E. dos. Economia Criativa: uma opção de desenvolvimento viável? In REIS, A.C.F. Economia criativa como estratégia de desenvolvimento: uma visão dos países em desenvolvimento. São Paulo: Itaú Cultural, 2008.

SOUZA, M. L. de. O Batismo de Fogo: a reforma neoliberal do governo Lula na previdência dos servidores públicos em um contexto de crise e restauração burguesa. Dissertação de Mestrado apresentada ao Programa de Pós-Graduação em Economia da UFU em 2006. 
Generalização da forma empresa expressa na política federal de cultura- um experimento da renovação do neoliberalismo| Patricia Tometich - Rosimeri Carvalho - Rodrigo Gameiro Guimarães

SMITH, A (1776). A riqueza das nações: investindo sobre sua natureza e suas causas. São Paulo: Abril Cultural, 1983. (Coleção os Economistas)

TURINO, C. Ponto de Cultura - o Brasil de Baixo Para Cima. Ed. Anita Garibaldi, 2009.

VASAPOLLO, Luciano. O trabalho atipico e a precariedade. São Paulo, Expressão Popular, 2005

WERNERFELT, B. A resource-based view of the firm. Strategic Management Journal, v. 5, n. 2, p. 171-180, 1984.

WILLIAMSON, O. The Economic Institutions of Capitalism. New York, Free Press. 1985, 450p. 